\title{
Modelling and implementing smart micro-grids for fish-processing industry
}

\author{
Ateyah Alzahrani, Ioan Petri, Yacine Rezgui \\ BRE Trust Centre for Sustainable Engineering \\ Cardiff University \\ Cardiff, United Kingdom \\ AlzahraniAA2@Cardiff.ac.uk
}

\begin{abstract}
Fish processing industries involve the usage of energy-intensive equipment, such as refrigerators, air conditioners and ice making machines leading to high energy costs and, indirectly, to an increase of the carbon emissions. As most fish industries sites are old, there is a strong need to make them more sustainable and achieve economic competitiveness in the energy market. Micro-grids have been utilised as efficient solutions in energy-intensive industries greatly balancing energy consumption and production at different scales. Smart micro-grids can also reduce carbon emissions by using renewable energy resources and applying smart energy management techniques.
\end{abstract}

In this paper, we propose a smart micro-grid system for fishprocessing industries with a validation use-case at Milford Haven Port in South Wales, UK. The system has been modelled using EnergyPlus and Matlab with the infinite grid, renewable energy resource, battery and charge/discharge controllers utilized for optimising energy consumption and production and for reducing carbon emissions. The preliminary results show that local power demand can meet the local power generation with the implementation of smart energy management techniques to support decision making for fish-processing industries.

Keywords-Energy; Micro-grid; Battery system; Fish industry; Demand and response; Carbon emissions

\section{INTRODUCTION}

The industrial sector accounts for $36 \%$ of the final energy consumption of electricity and contributes to about $20 \%$ of greenhouse gas emission [1]. The fish processing industries have the highest operating costs and energy consumption due to continuous refrigeration requirements, air conditioning and ice-making machines. Moreover, carbon emissions from the fishing industry have steadily increased due to the industry's high energy consumption and its continued use of fossil fuels. The emission from the global fishing industry grew by $28 \%$ from 1990 to 2011 [2]. European seaport organisation reports indicate that improving air quality and reducing energy consumption is amongst the top environmental priorities in port activities [3]. Therefore, the use of renewable energy resources provides long-term advantages by reducing carbon emission and minimising dependence on fossil fuels [4]. However, intermittency of renewable energy resources could affect the power management for fish industries, resulting in negative impacts on the operations during different periods [5]. This problem can be addressed by applying smart micro-grids that can utilise the energy excess for storage or for sharing within the local cluster [6]. The concept of smart grids was developed in 2005 by the European Technology Platform Smart Grids (ETPS). This was defined as an electricity network that can efficiently integrate the behavior and actions of all users connected to it (suppliers, consumers and those that do both) in order to ensure economic efficiency, and to provide sustainable power systems with low losses and high levels of quality, security of supply and safety [8]. The smart micro-gridcontrolled distribution networks act independently and can also operate in island mode. The advantage of smart micro-grids lies in providing stability in the system and reducing interaction with the grid, thereby lowering the transmission losses. By integrating renewable energy resources with the energy storage and load in a single network and implementing a smart energy management system, the intermittency of RES (Renewable Energy Sources) can be controlled and consisted [9].

Manolis at al., [10] conclude that the use of electricity in ports will rise in the next decades due to increasing operations and environmental factors. Authors suggest that ports represent promising areas to apply smart energy systems in order to meet the power demand and to increase the use of renewable energy resources. Also, renewable energy resources can bring the capability to meet power demand during sunshine or windy hours giving that some activities in ports can allow flexible electric loads such as cold storage, flake ice and cranes [10].

Atulya et al., [11] propose a system that uses a direct current micro-grid system drawing on renewable energy sources (solar, wind and biogas) to generate electric power for an Indian port. The authors report on installation of about $12 \mathrm{MW}$ of RES to meet daily power consumption exceeding $70000 \mathrm{kWh}$ with 440 energy storage units to meet continuous operation for port activities. The authors demonstrate how using real data of energy usage can help to achieve an accurate estimation of energy production [12]. Prousalidis et al., [13] also propose a 
smart grid model using a combination of smart grid techniques, renewable energy and cold ironing to meet the local power demand for vessels. The authors show how a system consisting of solar energy and wind turbines can automatically charge the battery system when there are no vessels to charge. The authors demonstrate that establishing smart grids with renewable energy sources and energy storage in ports can make a significant contribution towards integration with electricity markets based on demand-side response model [13]. This paper, instead, investigates the implementation of smart microgrid systems for fish processing industries by considering the applicability of energy grids from a technical and economic perspective. In addition, the study presents a methodology to determine the optimum size of the battery system for the Milford Haven port based on a control strategy approach. This is achieved by investigating the energy use for fish processing and maximising the use of renewable energy sources in energy clusters. Our modelling can advise on how to minimize carbon emissions and store the surplus of power in energy storage systems based on the local power demand at different time intervals. The proposed smart micro-grid model has been developed using multiple software applications allowing simulation of energy use in the local site and integration of different consumer agents. The remainder of this paper is as follows: in Section II we present the case study of the industrial fish site, in Section III we present the methodology adopted for developing the grid model. The proposed smart-grid is presented in Section IV, and results are reported in Section V. We conclude in Section VI.

\section{CASE STUDY}

\section{A. Milford Haven Port trial project}

The port of Milford Haven is a leading UK port, handling over 30 million tons of cargo annually. It is located in the western region of Wales and provides expertise in different marine operations such as cargo handling, renewables, freight, passenger ferry services, fisheries, commercial property management, leisure and retail [14]. The Milford Haven fish docks are located in an ideal place for vessels transitioning in the Irish Sea, Bristol Channel and the Celtic Sea. In the last few years, the port started to develop fish-processing units containing cold storages, ice-making machines and box washing machines [14].

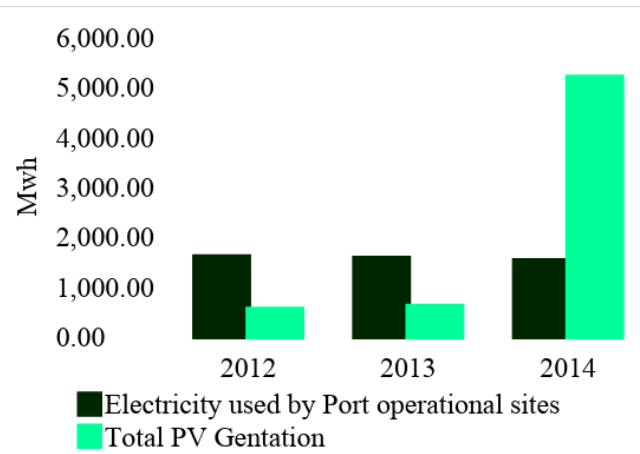

Figure 1: Total electricity consumption in Milford Haven port

\section{B. Energy Use at Milford Haven port}

The fish-processing industry at Milford Haven port is facing a real problem with increased energy consumption due to operational time at different seasons. According to the environmental report of Milford Haven port, the total power consumption of electricity in 2012 was about $1600 \mathrm{MWh}$, and the production of carbon emission is about 790 tones. The port authority has started to install PV panels across its facilities as an attempt to meet the increase in power demand and to eliminate carbon emissions in alignment with the UK 2050 plan of energy use. The port authority has installed 2500 panels across 25 buildings in its premises. Also, the port authorities have deployed a solar farm at Liddeston Ridge with more than 20000 panels and power capacity of 5 MW. Figure 1 presents the total power consumption and carbon emission of Milford Haven port from 2012 to 2014. For energy industries, the quantity of carbon emission can be reduced if the local power generation has the capability to meet local power demand and avoid the use of electricity from the national grid. The next sections will analytically examine power demands at Milford Haven port, assessing total power consumption and generation and propose the appropriate smart micro-grid model.

\section{METHODOLOGY}

We adopt a multi-stage approach with five stages of proposed methodology namely building simulation stage, energy generation simulation, energy storage simulation, grid model and integration of agents in Matlab/Simulink (Figure 2).

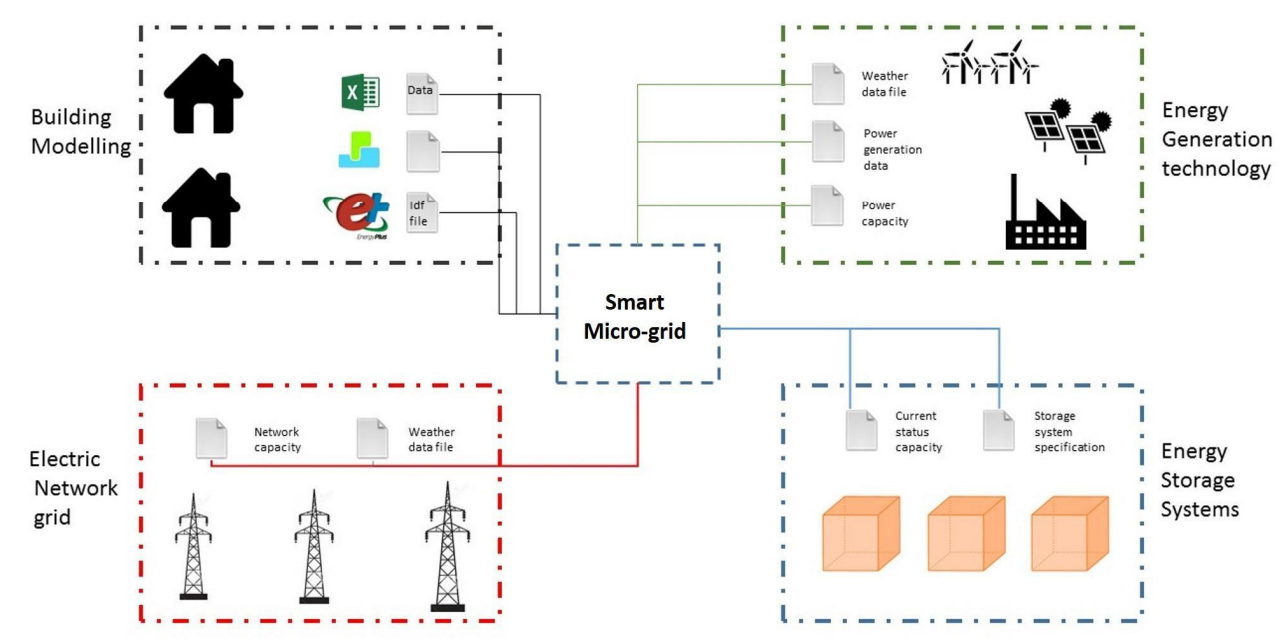

Figure 2: Smart micro-grid model of fish processing industry 


\section{A- Building Simulation Stage}

Step1: The first step of the methodology is to develop a model of electrical energy consumption for fishery ports using a software known as DesignBuilder (a commercial 3D modeller and energy simulation software platform). The thermal energy model includes geometrical information of the building enriched with occupancy information, material and envelope properties, overall intrinsic (including thermal properties) of the building, schedules for heating and cooling devices. The simulation model was generated based on a usecase scenario which involves minimizing electrical energy consumption in the Packaway building while maintaining acceptable $\mathrm{CO}_{2}$ emissions (see Figure 3). A description of the scenario is given in Table I.

Step 2: The next step is to simulate the process based on the different combinations of control variables. Initially, the thermal model has been generated using DesignBuilder and exported to EnergyPlus (an open-source and cross-platform energy simulation environment).

The Packaway building is the main building in the Milford Haven port and contains several appliances consuming energy: a flake ice machine, an ice store freezer, box washing machine, lighting systems and a smart meter. There are also four storage rooms in the Packaway building, and each storage room has a double tube lighting system. The box washing machine has a power capacity of $50 \mathrm{~kW}$, and it works only when the fisheries clean boxes during the day. The ice storage is under operation all the time to meet the demand for fish storage according to the quantity required. The Packaway building has installed a PV system on the roof of the building with $50 \mathrm{~kW}$ panels that feed the building at day time. They have a total power output of $275 \mathrm{~W}$ per panel with two DC-AC inverters. The building has been modelled using DesignBuilder simulation software. The model uses weather data, appliances, PV system, operation time and a load of appliances with capacity units. The Packaway building is the most power consuming building of the site with an annual power consumption of about $60000 \mathrm{kWh}$.

Table 1: List of the main appliances in Packaway building.

\begin{tabular}{|l|c|c|c|}
\hline Appliances & Quantity & Power (kW) & $\begin{array}{c}\text { Use } \\
\text { (hr/day) }\end{array}$ \\
\hline Cold Storage & 1 & 30 & 24 \\
\hline $\begin{array}{l}\text { Washing } \\
\text { machine }\end{array}$ & 1 & 50 & 5 minutes \\
\hline Lighting & 24 & $\begin{array}{c}11 \mathrm{~W} / \mathrm{per} \\
\text { lamb }\end{array}$ & 5 \\
\hline Flake ice & 1 & 30 & 4 \\
\hline Plug-in & 5 & 5 & 1 \\
\hline
\end{tabular}

Modelling and simulating of Packaway building will help to understand the total power consumption and generation and to determine the periods of the year that have the highest consumption. In addition, such energy modelling will help to identify the areas of energy optimization and a more informed calculation of the total amount of carbon emissions.

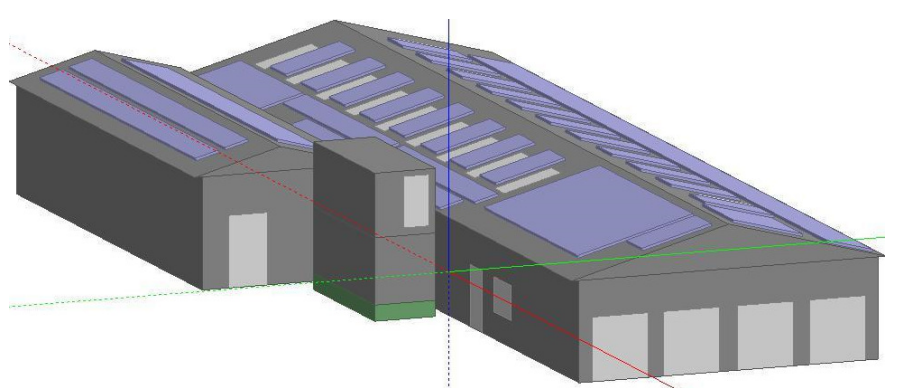

Figure 3: 3D-model of Packaway building in Milford Haven

DesignBuilder software facilitates the modelling of different variables of the building such as temperature, fuel consumption; heat balance system loads ventilation. In the Packaway building (see Figure 3 ) the focus was to assess the total annual power consumption and annual power generation with analysis of the energy consumption for specific appliances such as the lighting system, cooling, heating and other appliances.

Total electricity consumption of Packaway building

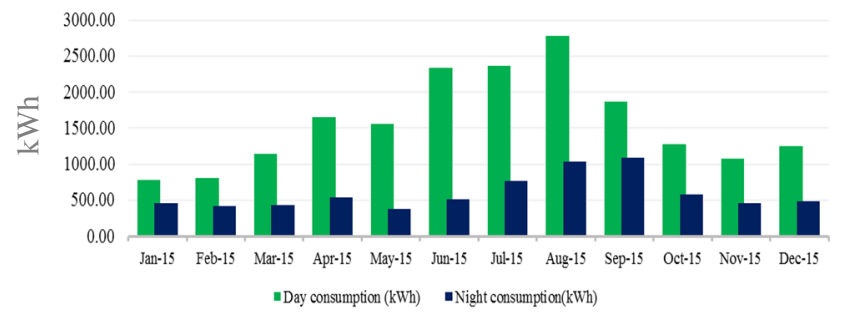

Figure 4: Simulation result of power consumption in Packaway

To conduct our modelling, DesignBuilder has been integrated with EnergyPlus engine simulation to calculate the total energy consumption of the Packaway building with further translations for the proposed smart microgrid.

\section{B- Energy generation and grid model}

EnergyPlus software was used to generate hourly power production for one year considering a 50-kW solar plant and associated inverters. EnergyPlus also uses the weather data of the fish industry site based on the latitude, longitude of the location. The EnergyPlus engine gives an output of the solar energy on an annual basis and also shows the hourly power generation and solar radiation. Figure 4 illustrates the total energy consumption in the Packaway building. The purpose of the grid is to supply any power demand to the property/building and take any surplus or positive power. As grids are used for their flexibility of feeding power, we have modelled the proposed grid at a frequency of $50 \mathrm{~Hz}$, based on 


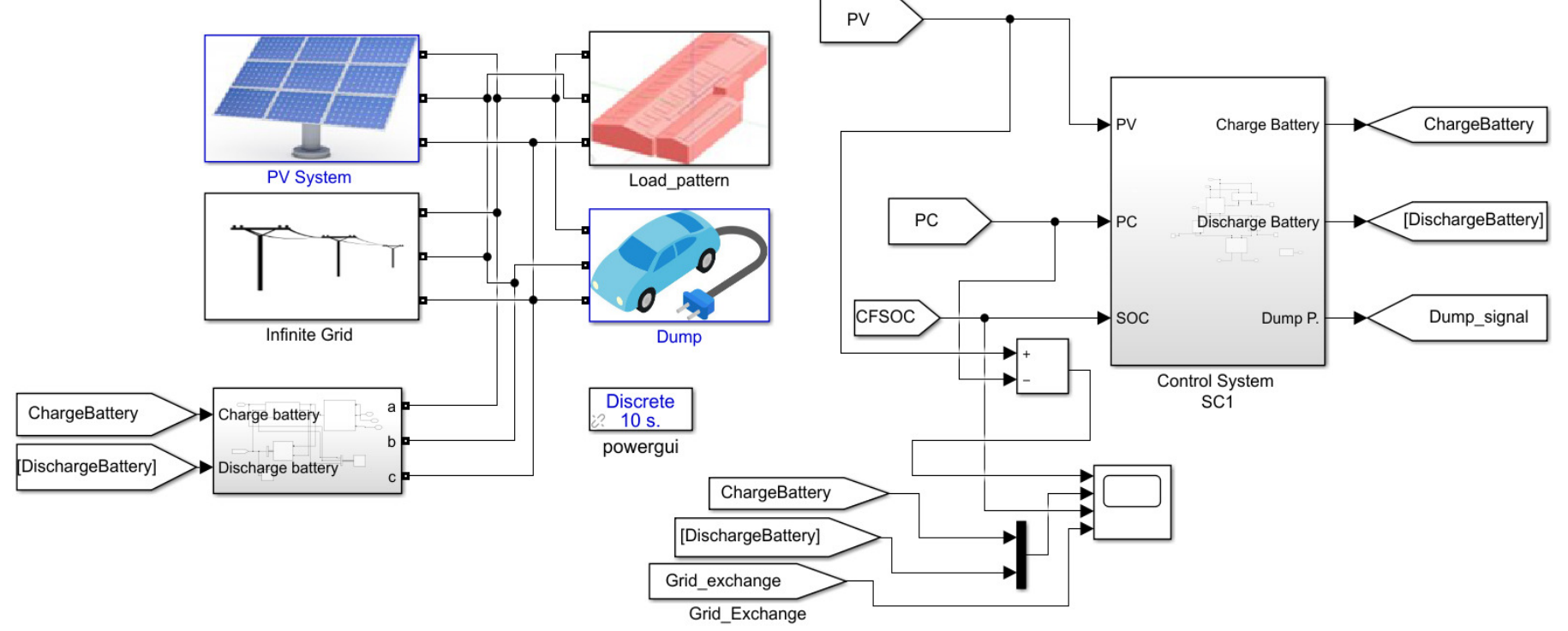

Figure 5: Proposed smart micro-grid using Matlab/Simulink

the European standards using Matlab/Simulink. Figure 5 illustrates the concept of the grid integration with the building load model.

\section{C- Energy storage systems}

The concept of "energy storage" depends on how much and how long a quantity of energy can be stored in relation to chemical, mechanical, thermal or electromagnetic techniques. Energy storage applications have developed with the radical transitions occurred within the energy systems of nations. There are different reasons for these changes such as climate change and mitigation policies which have led to the extensive use of renewables, particularly in Europe. At the shortest time scales, the most advanced form of electricity storage is when the quality of power supply is maintained within strict frequency standards. Electrochemical batteries are the most efficient solutions from all the various storage services available. They store and emit energy via electrochemical reactions which are extremely stable through a variety of operating conditions. Such batteries are capable of operating on short periods of time and have greater energy storage efficiency. New battery chemicals like Li-ion are far more effective than previous battery chemicals, and therefore are widely used for electric cars. For the Packaway building, a lithium-ion battery system has been used to cover the overall system with 12 volts and 100 A for each battery.

\section{PROPOSED SMART MICRO-GRID}

Smart micro-grid systems provide the opportunity for the fish-processing industry to become more sustainable. Introducing smart energy systems to the fish-processing industry will reduce the operation costs by reducing energy losses and efficiently using locally generated power. Howell et al., [8] suggest that applying smart grid technologies can be beneficial to an industry as a commitment to reducing carbon emissions and can portray such industry in a positive light with the public and within the industrial sector. For the Milford Haven site, we propose an integration between the load model, PV model, battery and the grid in order to achieve a better management and efficiency of the overall operation of the system. The signals generated during simulation are used to assess the load, power generation, grid and the battery's state of charge. Figure 5 presents the main components of the integration model for the Packaway building battery storage system. The building has a rooftop PV system with a capacity of $50 \mathrm{~kW}$ including a DC-DC converter and a DC-AC inverter. For the proposed smart grid model, the power generation is connected with the main appliances in the building and energy excess is configured to charge the battery system. The system has different priority levels whereby the energy produced is utilized for operating the appliances. When there is no demand from the building, the battery system is charged at a second priority level. When there is no demand and the battery is charged, the excess will be sent to the national grid. When there is no power generation from the PV system, the battery system connects with the building to meet the power demand. Similarly, if the battery system discharges when there is power demand from the building, the model will allow the provision of power from the national grid. The system has been tested with different battery capacities as a mean to identify the required number of battery systems that are required for the local power demand of the Packaway building for 12 months interval. 


\section{A- The main elements of smart micro-grid using Matlab/Simulink}

As in Figure 5, the smart micro-grid has several libraries related to power system components and utilizes an optimum battery size based on the input variables and time of running.

\section{1- Solar PV model}

The solar PV model has a capacity of $50 \mathrm{~kW}$, and the power output from PV is modelled as Direct Current (DC). However, this needs to be converted to Alternative Current (AC) which can be used to run different appliances in the building. A DC-DC converter produces a regulated output 3 phase voltages at $50 \mathrm{~Hz}$ and is used to feed generated power to grid at a standard 3 phase voltages. Figure 5 illustrates the schematic PV model that has been developed in Simulink.

\section{2- Packaway power consumption model}

A three-phase dynamic load model was created to receive power from a grid connection and to meet power demand. We consider a three-phase dynamic load implemented as a Simulink block which acts as a dynamic load for active power $\mathrm{P}$ and reactive power $\mathrm{Q}$, in the form of a function with positive-sequence voltage. As the load does not simulate the negative and zero-sequence currents, the load currents always remain balanced with no dependency on the voltages. The active and reactive load values can be specified as time series providing an optimal environment for simulating realistic load data. In the model, the block has a constant impedance that is triggered when the applied voltage is lower than a specified value Vmin. Figure 5 demonstrates that the load pattern changes when Voltage is higher than Vmin while the active and reactive power of load varies based on the following equations:

$$
\begin{array}{cl}
\text { Equation 1: } & P(s)=P_{0}\left(\frac{V}{V_{0}}\right)^{n_{p}} \frac{1+T{ }_{P^{1}} S}{1+T{ }_{P^{2}} S} \\
\text { Equation 2: } & Q(s)=P_{0}\left(\frac{V}{V_{0}}\right)^{n} \frac{1+{ }_{q^{1}} S}{1+T{ }_{q^{2}} S}
\end{array}
$$

Where

$-V_{0}$ is the initial positive sequence voltage.

$-P_{0}$ and $Q_{o}$ are the initial active and reactive power values at the initial voltage $\mathrm{V}_{\mathrm{o}}$.

$-V$ is the positive-sequence voltage.

$-n_{p}$ and $n_{q}$ are exponents (usually between 1 and 3 ) controlling the nature of the load.

$-T_{p 1}$ and $T_{p 2}$ are time constants controlling the dynamics of the active power $P$.

$-T_{q 1}$ and $T_{q 2}$ are time constants controlling the dynamics of the reactive power $Q$.

-For a constant current load, for example, set $n_{p}$ to 1 and $n_{q}$ to 1 , and for constant impedance load set $n_{p}$ to 2 and $n_{q}$ to 2 .

\section{3- Grid Model}

The purpose of the grid is to balance the system and take care of energy spikes in the system. The grid supplies any excessive power demand to the building and also absorbs the surplus of power. The infinite grid is used for the flexibility of feeding power demand and generation export of the system. For the Packaway building, the grid is connected with the PV system, load model and battery system with a frequency of $50 \mathrm{~Hz}$, based on the European standards.

\section{4- Battery system model}

An (Input_P) signal controls the battery model. From the controller, the signal is generated and sent to the model in the form of a command. The signal represents the difference between power generation from PV and power demand from the building. The signal indicates the need to charge or discharge the battery system. A positive signal means that the battery system is charging and the negative signal means discharging. The total amount of power is divided based on a battery voltage in order to find the current input for controlling current sources. Multiplying the voltage and the current will lead to determining the overall output power signal. The state of charge signal is generated and sent by a command to the main control block. In this model, a Lithiumion battery has been used with a nominal voltage of $12 \mathrm{Volt}$ and rated capacity of $1000 \mathrm{Ah}$ and with an initial state of charge of $50 \%$. Li-Ion batteries are chosen based on their electrochemical potential to provide energy density for weight. Li-Ion batteries are commonly used in portable electronics and their lifespan depletes with each discharge cycle.

\section{5- Charge and discharge Controller}

The algorithm of the charge/discharge controller is based upon a set of rules to distribute and manage the power system between the four agents. The scenario has two different models:

1- When Power consumption $(\mathrm{PC})=$ Power generation (PV), then all the power generation should feed the power consumption.

2- If power generation is greater than power consumption:

a- If yes, check the battery is full or not.

b- If the battery is full, then send the power generation to the national grid. Otherwise, charge the battery system.

If no, check the state of charge of the battery system. If the SOC greater than $20 \%$ then discharge power demand from the battery system. Otherwise, meet the power demand from the national grid. Figure 6 is a flow chart describing the charge and discharge controller processes. 
As presented in this section, there are several consecutive steps for developing the smart micro-grid system for the fishprocessing industry. The first step is to produce a simulation model for the fish industry. Before producing such a model, it is necessary to collect data from the site. This step is known as the walk-through auditing process, and it aims to provide data of all power consuming appliances and time of operation. The audit can help to understand the overall system and the design of the industrial site, with a clear idea of the operation. One of the biggest challenges encountered during the modelling process was the absence of actual readings of power consumption and generation. Moreover, the electricity consumption has been usually estimated by the power provider/utility company which impacts the accuracy of the overall modelling. After collecting data from the site, an EnergyPlus simulation model was developed to provide detailed data and patterns of energy use in the fish site.

This was followed by modelling the energy generation of the industrial site. The solar energy has been modelled with Matlab/Simulink based on the specification of PV panels, the location of site and weather data. The power consumption and power generation data were used for modelling the smart micro-grid and to determine the optimum operation of the system for the industry operations.

The system consists of multiple agents such as solar panels with inverters, Load pattern, battery system and the grid. There is also a charge and discharge controller that is required

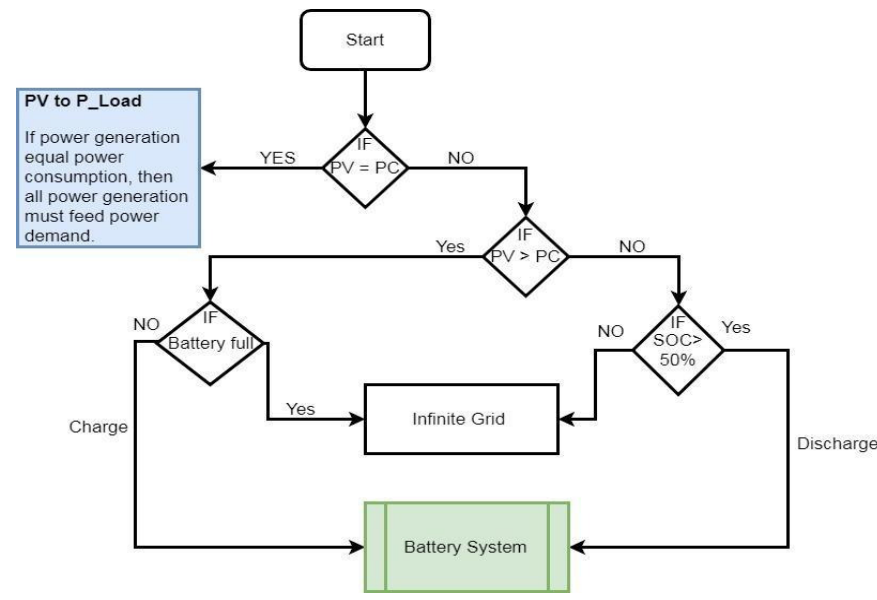

Figure 6: Flow chart diagram of charge and discharge controller

to control the battery system and the different agents. The simulation model has also been configured to identify the optimum number of batteries required to meet the power demand of the Packaway building.

Such batteries have the potential to motivate stakeholders to install power systems that will aid in reducing carbon emissions in fish industries while pursuing further research into whether fishery ports can produce positive energy and become zero carbon advocates.

\section{RESULTS}

The modelling and implementation of a smart micro-grid for fish industries represents a step forward and contributes to the development of energy consumption and production projections to promote more efficient operation within the industry. In this section,, we report on the proposed energy management concept in fish processing industries by proposing a smart micro-grid for increasing efficiency the overall industrial operation and energy management.

The simulation model of the smart grid has been developed based on four seasons. The model has been simulated based on random intervals in the seasons to observe the behaviour of the system under different situations. In addition, the model enables the investigation of the optimum battery storage capacity based on the state of charge per day. The results of the smart micro-grid simulation reflect the flow of charge and discharge with a curve of differential power generation and power consumption for the Packaway building for each season.

Figure 7 presents the state of power consumption and power generation for the Packaway building based on the control charge model. The smart grid model utilizes an algorithm

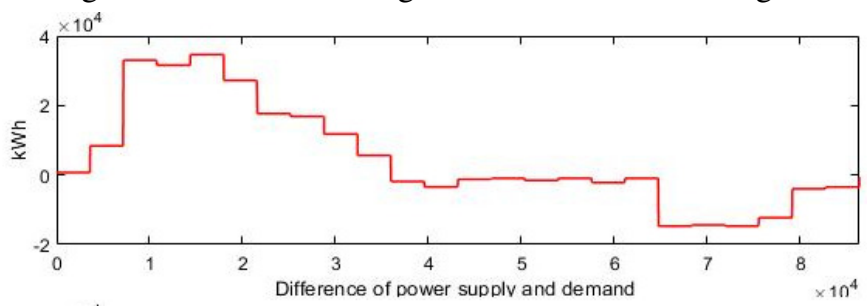

Figure 7: Difference of power consumption and power generation

based on which energy is exchanged within system components. When the power generation equals the power demand, then all power generation should be used for power consumption. So, it is important to determine the state of the power supply and demand and to identify variability in the consumption intervals. Figure 7 illustrates the power supply and demand for one day where the difference between power supply and demand has been determined based on a control strategy during the simulation phase. Moreover, we have implemented a granular data modelling process which improves the accuracy and determines the exact response from the battery charge and discharge controller.

Figure 8 demonstrates the charge and discharge controller during the evaluated period.

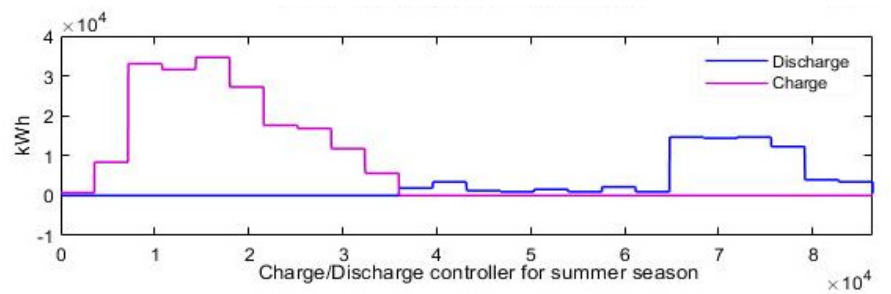

Figure 8: Charge and discharge controller of the summer 
Based on the smart-grid modelling, the power generation is scheduled to operate the appliances in the building whereas the power generation excess will go to the battery system (charging mode). Conversely, if the battery system is full, the power will be exported to the national grid. During night time, however, when there is no power generation from the solar system, the power demand can be met from the local battery system (discharging mode). If the power in the battery system does not have sufficient capacity to meet the demand, then energy from the national grid will be used. Figure 9 shows the state of charge of the battery system for four seasons.: (a) State of charge (SOC) for winter, (b) SOC for spring (c) SOC for summer and (d) SOC for autumn. The system has been tested in a random period within the four seasons to identify the behaviour of the operating process and the optimum number of battery systems. For example, during the winter the solar radiation is lower during the day, which
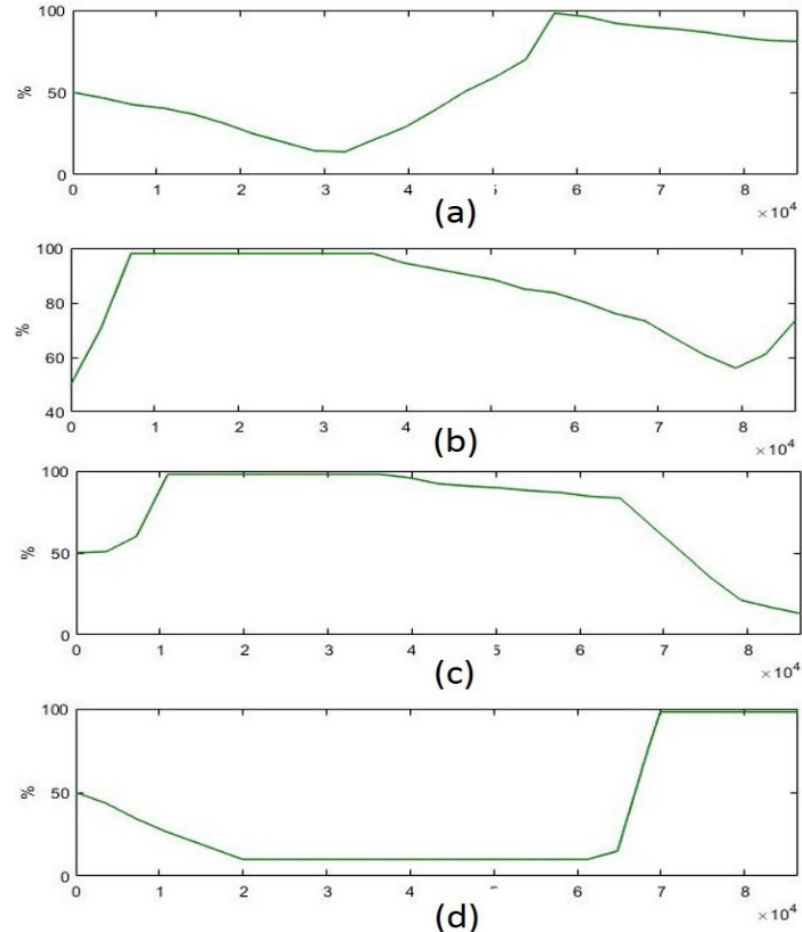

Figure 9 State of charge for 4 seasons [ $a-$ winter, bspring, c-summer d-autumn]

will reflect on the optimum number of battery systems required to store the energy excess. Based on the analysis, it has been found that the optimum number of battery storage is about 2000 A per hour which is about 20 LI-IO batteries. However, the size of the battery has been calculated based on a random period in winter. To get the optimum number of battery modules, it is necessary to run the model for four months which requires the utilization of a high-performancecomputing infrastructure. The result of the simulation was produced from a Windows 7 PC, Intel (R) Core (TM) i76700K CPU @ 4 GHz with16 GB RAM. Therefore, to get an optimum result, it was necessary to run the model for a longer period in winter, a simulation process that took between 5 to 6 hours to complete.
From Figure 9, it is observed that the system in spring needs more battery. However, discussions with the staff on the site revealed that spring and summer are hot seasons for fishers which means that the industry should be in operation mode at least from 12 to 18 hours on a daily basis. This indicates the need to increase the number of battery systems in spring which led to the determination of an optimum number of batteries capacity during the summer of about $7500 \mathrm{~A}$.

There are many reasons for increasing the number of battery systems in the summer. As in the day time, energy production during the summer in Milford Haven averages from 15 to 19 hours, an increased number of batteries is required to augment the charge so as to meet the local power demand and to utilize the solar energy system during this season. The simulation results in Table 2 show that the optimum size of batteries for the fish industry in Milford Haven in autumn is about 5000 A.

Table 2: Battery performance tests

\begin{tabular}{|c|c|c|c|c|c|c|c|}
\hline \multirow{2}{*}{ Day/month } & \multirow{2}{*}{$\begin{array}{l}\text { Day/ } \\
\text { month }\end{array}$} & \multicolumn{2}{|c|}{$\begin{array}{l}\text { Period } \\
\text { (hours) }\end{array}$} & \multirow{2}{*}{ Type } & \multirow{2}{*}{$\begin{array}{c}\text { Battery } \\
\text { capacity } \\
\text { Ah }\end{array}$} & \multirow{2}{*}{$\begin{array}{l}\text { Battery } \\
\text { Voltage }\end{array}$} & \multirow{2}{*}{$\begin{array}{c}\text { Battery } \\
\text { performance }\end{array}$} \\
\hline & & From & To & & & & \\
\hline $1 \mathrm{Jan}$ & 28 Jan & 0 & 672 & Li-Io & 200 & 12 & $84.5 \%$ \\
\hline $1 \mathrm{Jan}$ & $28 \mathrm{Feb}$ & 0 & 1417 & Li-Io & 200 & 12 & $71.1 \%$ \\
\hline $1 \mathrm{Jan}$ & $31 \mathrm{Mar}$ & 0 & 2161 & Li-Io & 200 & 12 & $43.06 \%$ \\
\hline $1 \mathrm{Jan}$ & $31 \mathrm{Mar}$ & 0 & 2161 & Li-Io & 300 & 12 & $55 \%$ \\
\hline $1 \mathrm{Jan}$ & $31 \mathrm{Apr}$ & 0 & 2881 & Li-Io & 400 & 12 & $31.5 \%$ \\
\hline 1 Jan & $31 \mathrm{Apr}$ & 0 & 2881 & Li-Io & 600 & 12 & $63.5 \%$ \\
\hline 1 Jan & 31 May & 0 & 3625 & Li-Io & 800 & 12 & $57.5 \%$ \\
\hline 1 Jan & 30 June & 0 & 4345 & Li-Io & 1000 & 12 & $58.2 \%$ \\
\hline 1 Jan & $31 \mathrm{Jul}$ & 0 & 5089 & Li-Io & 1100 & 12 & $53.91 \%$ \\
\hline $1 \mathrm{Jan}$ & $31 \mathrm{Aug}$ & 0 & 5833 & Li-Io & 1200 & 12 & $51.2 \%$ \\
\hline 1 Jan & $31 \mathrm{Sep}$ & 0 & 6554 & Li-Io & 1400 & 12 & $56.6 \%$ \\
\hline $1 \mathrm{Jan}$ & $31 \mathrm{Oct}$ & 0 & 7297 & Li-Io & 1600 & 12 & $61.5 \%$ \\
\hline 1 Jan & $31 \mathrm{Nov}$ & 0 & 8017 & Li-Io & 1700 & 12 & $64.9 \%$ \\
\hline $1 \mathrm{Jan}$ & $31 \mathrm{Dec}$ & 0 & 8761 & Li-Io & 1800 & 12 & $62.5 \%$ \\
\hline
\end{tabular}

The results in Figure 9, show that the system initially identified a typical stable state with no high-power consumption followed suddenly by an increase to a full charge after the sunrise. The battery model as presented in the overall smart grid model facilitates the understanding of power management in the fish industry and determines new ways to optimize the generation of energy alongside a smarter use of electricity in the industry.

\section{CONCLUSION}

Building Information Models (BIM) provide a useful basis to asses the energy performance of buildings [15, 16]. This study investigates energy use in fish industries by proposing a smart, novel and efficient energy model to manage consumption and production. The smart micro-grid model has been proposed to reduce the dependence on fossil fuel and to reduce carbon emission by integrating renewable energy resources and adopt smart energy management systems. The smart energy grid model has been implemented for the Milford Haven port in South Wales, UK. The system has been modelled using EnergyPlus and Matlab/Simulink with results demonstrating that local power demand could be meet by local power generation using smart micro-grids. It has been demonstrated that $50 \mathrm{~kW}$ capacity of a PV system 
can meet the local power demand with the integration of LIIO battery system of 12 Volt which has the capability to manage the power flow for different periods.

By presenting this real trial project, we aim to observe what mechanisms from the simulation module are applicable to the real smart grid project and find new ways to optimise energy consumption and production for industrial sites.

Further research will be undertaken to test different types of battery systems and to identify the optimum storage capacity. Also, prediction and optimization of power demand and power supply using artificial intelligent techniques will be explored as a means to manage energy in such a fish industry grid context more efficiently.

\section{ACKNOWLEDGEMENT}

This work is part of the EU INTERREG piSCES Project: "SmartCluster Energy System for the Fish Processing Industry.", grantnumber: 512429

\section{REFERENCES}

1. Agency, E.E. Total greenhouse gas emission trends and projections. 2018 [cited 2019 8/1/2019]; Available from: https://www.eea.europa.eu/dataand-maps/indicators/greenhouse-gas-emissiontrends-6/assessment-2.

2. $\quad$ Parker, R.W.R., et al., Fuel use and greenhouse gas emissions of world fisheries. Nature Climate Change, 2018. 8(4): p. 333-337.

3. Organisation, E.S.P., Environmental Report 2018 (EcoPortsinSights 2018). 2018: BRUSSEL

4. Misra, A., et al., GHG emission accounting and mitigation strategies to reduce the carbon footprint in conventional port activities-a case of the Port of Chennai. Carbon Management, 2017. 8(1): p. 4556.

5. Chiş, A., et al. Demand response for renewable energy integration and load balancing in smart grid communities. in Signal Processing Conference (EUSIPCO), 2016 24th European. 2016. IEEE.

6. Hong, Y., et al. Discovering energy communities for microgrids on the power grid. in Smart Grid Communications (SmartGridComm), 2017 IEEE International Conference on. 2017. IEEE.

7. Gungor, V.C., et al., Smart grid technologies: Communication technologies and standards. IEEE transactions on Industrial informatics, 2011. 7(4): p. 529-539.

8. Yoldaş, Y., et al., Enhancing smart grid with microgrids: Challenges and opportunities. Renewable and Sustainable Energy Reviews, 2017. 72: p. 205-214.

9. Howell, S., et al., Towards the next generation of smart grids: Semantic and holonic multi-agent management of distributed energy resources. Renewable and Sustainable Energy Reviews, 2017. 77: p. 193-214.
10. Manolis, N., et al. MAS Based Demand Response Application in Port City Using Reefers. in International Conference on Practical Applications of Agents and Multi-Agent Systems. 2017. Springer.

11. Misra, A., et al., Renewable Energy Based Smart Microgrids-A Pathway To Green Port Development. Strategic Planning for Energy and the Environment, 2017. 37(2): p. 17-32.

12. NASA. What Are Climate and Climate Change? 2011; Available from: https://www.nasa.gov/audience/forstudents/58/features/nasa-knows/what-is-climate-change58.html.

13. Prousalidis, J., et al., The ports as smart microgrids: development perspectives. Proceedings of HAEE, 2017: p. 12-16.

14. Haven, P.o.M. Energy, Renewables \& Engineering. 2019 [cited 2019 18/02/2019]; Available from: https://www.mhpa.co.uk/.

15. Vorakulpipat, $\mathrm{C}$ and Rezgui, Y. Value creation: The future of knowledge management. Knowledge Engineering Review, 23(3), 2008: p. 283-294. DOI: $10.1017 / \mathrm{S} 0269888908001380$

16 Gupta, A., Cemesova, A, Hopfe, C.J, Rezgui, Y., Sweet, T. A conceptual framework to support solar PV simulation using an open-BIM data exchange standard, Automation in Construction, 37, 2014, p. 166-181. DOI: 10.1016/j.autcon.2013.10.005 